\title{
Snowfall Retrievals Using Millimeter-Wavelength Cloud Radars
}

\author{
Sergey Y. Matrosov, Matthew D. Shupe, and Irina V. Djalalova \\ Cooperative Institute for Research in Environmental Sciences, University of Colorado, and NOAA/Earth System Research \\ Laboratory, Boulder, Colorado
}

(Manuscript received 25 April 2007, in final form 27 June 2007)

\begin{abstract}
It is demonstrated that millimeter-wavelength radars that are designed primarily for cloud studies can be also used effectively for snowfall retrievals. Radar reflectivity-liquid equivalent snowfall rate $\left(Z_{e}-S\right)$ relations specifically tuned for $\mathrm{K}_{\mathrm{a}}-$ and $\mathrm{W}$-band radar frequencies are applied to measurements taken by vertically pointing ground-based 8-mm cloud radars (MMCR) that are designed for the U.S. Department of Energy's Atmospheric Radiation Measurement (ARM) Program and by the nadir-pointing spaceborne 94-GHz CloudSat radar. Comparisons of the MMCR-based snowfall accumulations estimated during experimental events with no significant snowflake riming and controlled gauge measurements indicated an $87 \%$ standard deviation between radar and gauge data that is consistent with the uncertainties in the coefficients of the $Z_{e}-S$ relations resulting from variability in snowflake microphysical properties. Comparisons of CloudSat-based snowfall-rate retrievals in heavy snowfall were consistent with estimates from surface S-band precipitation surveillance radars made using algorithms that were specifically designed for use with these radars. A typical difference between the CloudSat and the S-band precipitation radar estimates of snowfall rate for approximately collocated resolution pixels was within a factor of 2, which is of the order of the uncertainty of each estimate. The results of this study suggest that the ground-based and satellite-borne radars operating at $\mathrm{K}_{\mathrm{a}}$ and $\mathrm{W}$ bands can provide valuable retrieval information on vertical profiles of snowfall, which is an important component of the global water cycle. This information is particularly important in Arctic regions where precipitation information from other sources is scarce.
\end{abstract}

\section{Introduction}

Traditional radar-based methods for estimating precipitation use relations between the equivalent radar reflectivity factor $Z_{e}$ and the rain rate $R$ or melted liquid equivalent snowfall rate $S$. These relations generally exhibit more variability in their coefficients for snowfall than for rainfall, owing to larger uncertainties in snowflake habits and fall velocities relative to those in raindrops. Although the use of polarimetric radar data can offer significant improvements for quantitative rainfall estimations (e.g., Bringi and Chandrasekar 2001) for scanning radar systems, radar snowfall measurements still largely rely on $Z_{e}-S$ relations because natural changes in snowflake shapes and densities result in significant variability of polarimetric radar measurables. This variability makes it difficult to employ polarimetric approaches for snowfall studies.

Corresponding author address: Dr. Sergey Matrosov, R/PSD2, 325 Broadway, Boulder, CO 80305.

E-mail: sergey.matrosov@noaa.gov
Longer-wavelength radars such as those operating at $\mathrm{S}$ band (10-11-cm wavelength $\lambda), \mathrm{C}$ band $(\lambda \sim 5-6 \mathrm{~cm})$, or $X$ band $(\lambda \sim 3 \mathrm{~cm})$ are typically used for quantitative precipitation estimations. Millimeter-wavelength radars that use $\mathrm{K}_{\mathrm{a}}$-band $(\lambda \sim 8 \mathrm{~mm})$ or W-band $(\lambda \sim 3$ $\mathrm{mm})$ frequencies were originally intended for nonprecipitating-cloud studies, and they are often used in the vertical (i.e., nadir or zenith looking) measurement mode. It has been shown, however, that these radars can also provide valuable precipitation information. Whereas attenuation-based techniques were shown to be useful for quantitative rainfall retrievals at millimeter wavelengths (Matrosov 2005; Matrosov et al. 2006), it is expected that snowfall-rate retrievals can be useful using traditional radar approaches with $Z_{e}-S$ relations that are specifically adjusted for cloud radar frequencies (Matrosov 2007a).

Unattended vertically pointing ground-based 8-mmwavelength cloud radars (MMCR) have been operated continuously for a number of years at different Arctic locations, including the North Slope of Alaska (NSA) site of the U.S. Department of Energy's Atmospheric 
Radiation Measurement (ARM) Program (e.g., Kollias et al. 2005) and an atmospheric observatory at Eureka, Canada. A number of MMCR-type radars are also used in colder climates during extended temporal deployments (e.g., Uttal et al. 2002). The long-term records of cloud observations are then used to retrieve cloud microphysical properties that largely determine the cloud radiative effects. The addition of vertically resolved retrievals of snowfall can provide a more complete characterization of the atmospheric column above the observatories equipped with vertically pointing radars and offer new insights on snowfall initiation and development processes, climate, and water-cycle studies.

The snowfall information from vertically pointing radars is valuable for many applications and can provide annual cycle characteristics, but it lacks the spatial coverage. CloudSat (Stephens et al. 2002), the first spaceborne polar-orbiting W-band cloud radar, launched in April of 2006, offers a unique opportunity to provide vertically and spatially $(\sim 1.5-\mathrm{km}$ footprint $)$ resolved precipitation information, especially in the large parts of the polar regions where the satellite coverage is more frequent and surface-based observations are scarce or nonexistent. It has been shown that CloudSat can provide information on rainfall (e.g., Matrosov 2007b). Because snowfall often provides a major fraction of polarregion precipitation, CloudSat snowfall retrievals can be particularly useful there.

This study illustrates the utility of snowfall estimates using $Z_{e}-S$ snowfall relations for millimeter-wavelength cloud radars. The need of such estimates is dictated by a relative scarcity of solid precipitation data (especially in the Arctic), and the opportunity in getting these estimates arises from measurements that are now available from continuously operating cloud radars. Note that radar-only estimates based on $Z_{e}-S$ snowfall relations are one of only a few viable options for snowfall vertical profile retrievals with millimeter-wavelength radars. The addition of optical instrument measurements (e.g., infrared radiometer and/or lidar data) that often are used in conjunction with cloud radar measurements for multisensor retrievals of ice clouds with optical depth of less than about 3-4 are not generally adjustable to precipitating systems because the optical depth of such systems is typically high.

\section{An illustration of MMCR snowfall retrievals}

A customary way of expressing $Z_{e}-S$ relations at all radar frequencies is a power law:

$$
Z_{e}\left(\mathrm{~mm}^{6} \mathrm{~m}^{-3}\right)=a S^{b}\left(\mathrm{~mm} \mathrm{~h}^{-1}\right) .
$$

Because of relatively strong non-Rayleigh scattering, snowfall $Z_{e}-S$ relations at $\mathrm{K}_{\mathrm{a}}$-band radar frequencies differ considerably from those that are typically used to derive precipitation information from centimeter-wavelength radar measurements. Based on modeling using in situ data and theoretical considerations (Matrosov 2007a), it was suggested that average values for the coefficient $a$ and the exponent $b$ in Eq. (1) for $\mathrm{K}_{\mathrm{a}}$ band are about 56 and 1.2, respectively, if snowfall is "dry" (i.e., snowflakes are not wet and do not exhibit significant riming). The relative variability of the coefficient in Eq. (1) resulting from the model uncertainties is about $\pm 50 \%$ or so, whereas the relative variability of the exponent is generally more modest $( \pm 10 \%)$. These uncertainties can result in snowfall-rate retrieval errors that are as high as a factor of 2 or even greater.

The first three panels of Fig. 1 show time-height cross sections of spectral Doppler moments (i.e., the reflectivity factor $Z_{e}$, the Doppler velocity $V_{D}$, and the Doppler spectral width $\sigma_{w}$ ) measured by the NSA MMCR in the precipitation mode during an event of 27 September 2004. This mode has the highest Nyquist velocity $\left(\sim 7.4 \mathrm{~m} \mathrm{~s}^{-1}\right)$ for unambiguous measurements of precipitating hydrometeors (Kollias et al. 2005). The 27 September 2004 event is representative of snowfalls observed at the NSA site, and therefore it is instructive to analyze it in relative detail.

Although $V_{D}$ and $\sigma_{w}$ are not directly used for snowfall-rate retrievals, they provide useful qualitative information about snowfall. For most of the event, typical values of the vertical Doppler velocity are less than about $1.3 \mathrm{~m} \mathrm{~s}^{-1}$, which is indicative of no significant snowflake riming (Mosimann 1995). The relative "dryness" of the falling snow was also indirectly confirmed by estimates of total liquid water path (LWP) from the vertically pointing microwave radiometer data (not shown). These data indicated that prior to 2100 UTC LWP values were generally less than about $50 \mathrm{~g} \mathrm{~m}^{-2}$ which is close to the uncertainty of the LWP estimates. Generally higher values of $V_{D}$ after about 2100 UTC were accompanied by a large increase of LWP, the value of which exceeds about $100-200 \mathrm{~g} \mathrm{~m}^{-2}$, indicating an increase in supercooled liquid water and, hence, snowflake riming. The presence of supercooled liquid water in Arctic clouds occurs frequently even at low temperatures (Shupe et al. 2006). The high temporal variability of mean Doppler velocity is evident in the lowest $1.5-\mathrm{km}$ layer, where $V_{D}$ values oscillate between about 1.8 and $0.8 \mathrm{~m} \mathrm{~s}^{-1}$. This behavior can be explained by turbulence, which is also consistent with large Doppler spectral widths $\sigma_{w}$.

Figure 2 shows the mean vertical profiles of MMCR reflectivity, mean Doppler velocity, and retrieved 

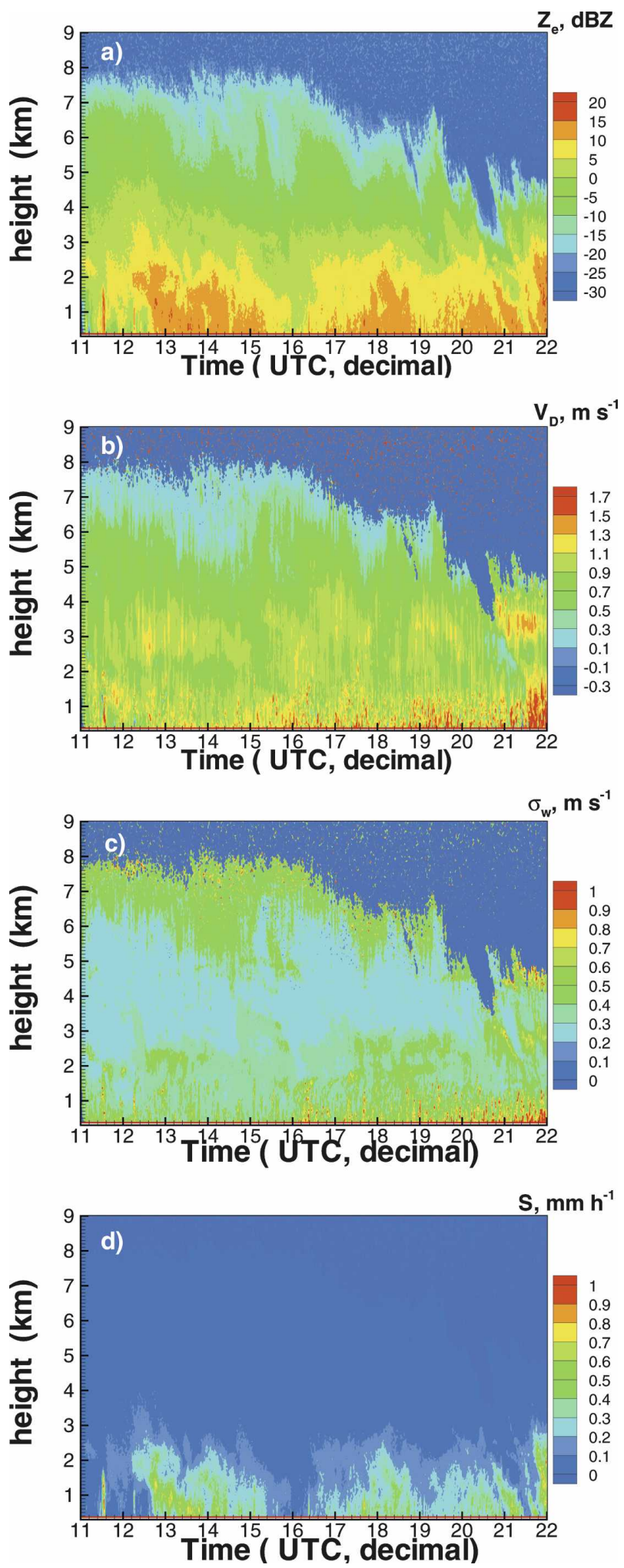

FIG. 1. Time-height cross sections of (a) MMCR reflectivity, (b) vertical Doppler velocity, (c) Doppler spectral width, and (d) retrieved snowfall rate for a snowfall event observed at the ARM NSA site on 27 Sep 2004.

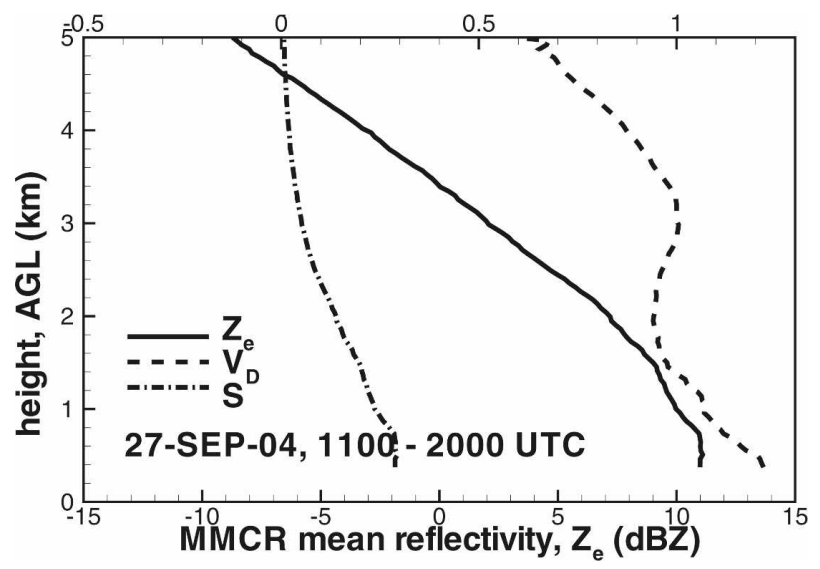

FIG. 2. Average vertical profiles of the MMCR reflectivity and vertical Doppler velocity for the NSA event observed on 27 Sep 2004.

snowfall rate for the considered event. For heights greater than $1.5 \mathrm{~km}$ above ground level (AGL), the vertical gradient of the reflectivity is nearly constant at about $4 \mathrm{~dB} \mathrm{~km}^{-1}$. Note that instantaneous profiles (as seen in Fig. 1a) can exhibit reflectivity maxima aloft. Unlike $Z_{e}$, the mean $V_{D}$ profile does not vary much below $3 \mathrm{~km}$ AGL even if a square root air density $\left(\rho_{\text {air }}\right)$ correction is used to recalculate $V_{D}$ for surface reference values $V_{D}^{(s)}\left\{V_{D}^{(s)}=V_{D}\left[\rho_{\text {air }} / \rho_{\text {air }}^{(s)}\right]^{0.5}\right\}$. This result is consistent with theoretical findings of Mitchell and Heymsfield (2005), who showed that there is very little dependence of snowflake fall velocities on their sizes for sizes between a few millimeters and $1-2 \mathrm{~cm}$. Such sizes are typical for snowflakes observed in snowfall that produces appreciable accumulation. This fact also means that there is little quantitative information contained in the mean Doppler velocity of unrimed (or only moderately rimed) snowflakes. This is in contrast to cirrus-cloud retrievals (i.e., Matrosov et al. 2002; Mace et al. 2002) in which, for smaller ice crystals $(<1$ $\mathrm{mm}$ ), there is a good correlation between $V_{D}$ and characteristic crystal size. The vertical Doppler velocity, however, does provide useful qualitative information that allows discrimination among snowfall events with different degrees of snowflake riming (Mosimann 1995).

Time-height cross sections of snowfall-rate retrievals based on Eq. (1) are depicted in Fig. 1d, and the mean profile is shown in Fig. 2. Attenuation in MMCR signals in snow was ignored for these retrievals because attenuation effects at $\mathrm{K}_{\mathrm{a}}$ band are expected to be small in this mostly dry snowfall (Matrosov 2007a). Figure 3 shows the time series of the MMCR-derived snowfall rate and accumulation as calculated at the lowest MMCR gate ( $\sim 350 \mathrm{~m} \mathrm{AGL})$ where echo signals are out of the re- 


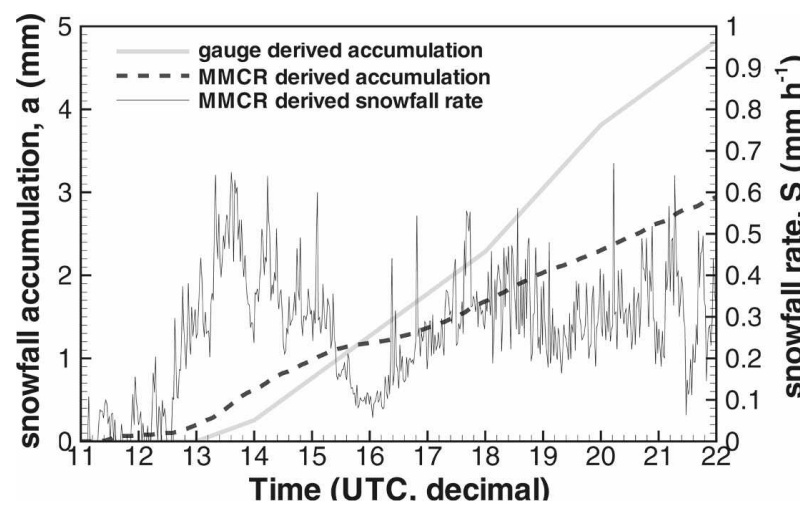

FIG. 3. Time series of the snowfall accumulations and snowfall rate for the NSA event observed on 27 Sep 2004.

ceiver saturation regime. Also included in this figure is a time series of the snowfall liquid equivalent accumulation measured near the ARM NSA site by the shielded automatic Geonor, Inc., T-200 tipping-bucket snow gauge [0.01-in. $(0.0254 \mathrm{~cm})$ resolution] which is deployed as part of the Climate Reference Network (http://www.ncdc.noaa.gov).

There is a general agreement within $30 \%$ between the gauge and MMCR accumulation data, although the rate of the accumulation increase for the MMCR retrievals is slower than for gauge estimates, especially after about 1800 UTC. Part of the MMCR-gauge discrepancy can be attributed to the difference between the surface snowfall and snowfall at the lowest available MMCR range ( $\sim 350 \mathrm{~m}$ AGL). This difference, however, is not expected to be very large because the mean vertical gradient of the reflectivity is generally smaller near the surface than aloft (see Fig. 2). Some theoretical and in situ aircraft measurements (e.g., Mitchell 1988) also indicated smaller snowfall-rate changes near the ground relative to those at higher altitudes. Uncertainties and/or biases in measured reflectivity values and uncertainties in the coefficients of the $Z_{e}-S$ relations (Matrosov 2007a) can also influence radar-based retrievals. There are strong indications that some biases existed in the NSA MMCR data for the last several years (S. Moore, ARM, 2007, personal communication).

\section{Statistical comparisons of MMCR snowfall accumulation data with gauges}

Although comparisons of the radar and snow gaugederived accumulations in Fig. 3 are a useful consistency check, they cannot be considered as a strict validation effort because of the high uncertainties associated with both types of measurements. The unattended gauge measurement uncertainties could be comparable to
TABLE 1. SHEBA snowfall events.

\begin{tabular}{lcc}
\hline \hline \multicolumn{1}{c}{ Date } & $\begin{array}{c}\text { Radar estimate } \\
(\mathrm{mm})\end{array}$ & $\begin{array}{c}\text { Snow gauge } \\
\text { estimate }(\mathrm{mm})\end{array}$ \\
\hline 11 Nov 1997 & 0.35 & 0.69 \\
29 Nov 1997 & 0.60 & 0.85 \\
1 Jan 1998 & 7.20 & 12.4 \\
16 Mar 1998 & 7.80 & 3.20 \\
21 Mar 1998 & 2.65 & 1.42 \\
1 Apr 1998 & 2.42 & 1.02 \\
2 Apr 1998 & 3.95 & 1.74 \\
17 Apr 1998 & 1. & 3.93 \\
19 Sep 1998 & 1.25 & 2.00 \\
1 Oct 1998 & 0.92 & 1.34 \\
\hline
\end{tabular}

those from the radar estimates. Thus, it is of interest to make snowfall accumulation comparisons with measurements from an attended snow gauge that has been corrected for environmental conditions that could impact the measurement. Such a gauge was in operation, in coordination with a well-calibrated MMCR radar, at the yearlong Surface Heat Budget of the Arctic Ocean (SHEBA) experiment held in the Arctic Ocean north of Alaska (Uttal et al. 2002).

A Nipher-type shielded snow gauge was deployed during SHEBA in the vicinity $(\sim 200 \mathrm{~m})$ of the radar. The snow caught by this gauge after each snowfall event was melted and measured in a special graduated glass cylinder to obtain the water equivalent. The gauge was regularly attended by an operator, and the quality of the snowfall accumulation measurements was constantly monitored. Procedures to correct the gauge data for the effects of wind, evaporation, and wetting (i.e., losses resulting from water retained on the walls of the cylinder) were introduced according to Goodison and Yang (1996). Despite the corrections and regular quality controls, the uncertainty of snow gauge measurements is expected to be higher than the typical $10 \%-$ $15 \%$ uncertainty for rain gauges.

Table 1 shows significant snowfall events observed during the SHEBA experiment that can be classified as cases with no or insignificant snowflake riming. Estimates of average radar mean Doppler velocities and LWP values derived from microwave radiometer measurements were used to identify these events. The liquid equivalent total snowfall accumulations estimated from MMCR measurements using Eq. (1) at the lowest nonsaturated gate (typically at $\sim 350 \mathrm{~m} \mathrm{AGL}$ ) and the quality-controlled corrected gauge data are also shown in Table 1. According to the gauge, the significant event accumulations varied during SHEBA from about 0.7 to $12.4 \mathrm{~mm}$.

The scatterplot of MMCR-based snowfall accumulation estimates versus the gauge data is shown in Fig. 4. 


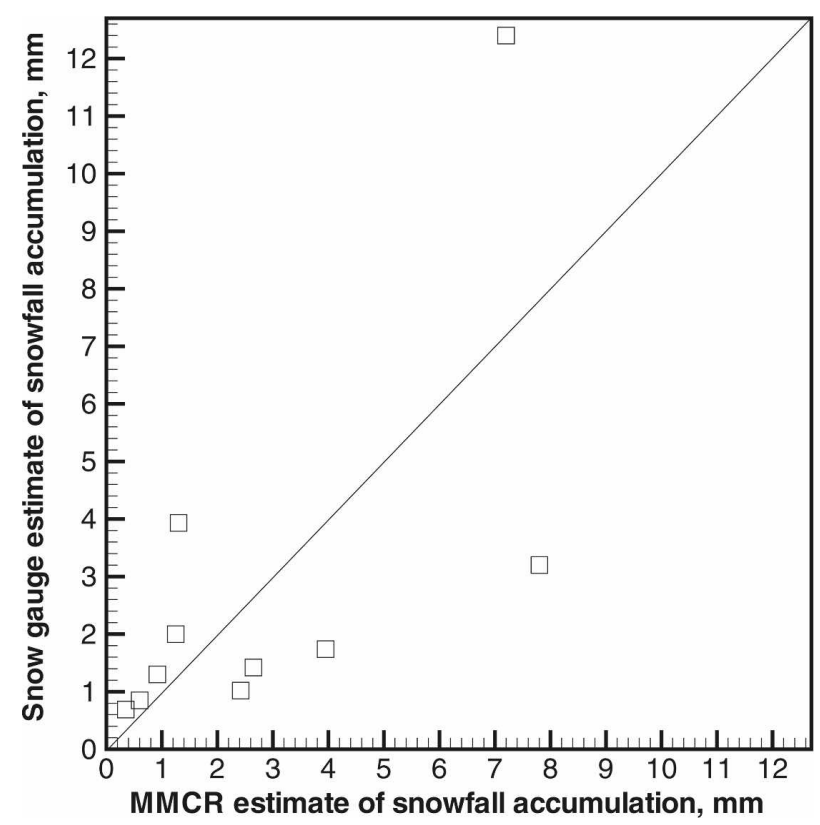

FIG. 4. A scatterplot of SHEBA snowfall accumulations derived from MMSR and from snow gauge measurements.

The average relative bias (RB) between the radarderived data and gauge measurements is $23 \%$, and the relative standard deviation (RSD) is $87 \%$. The RB value is small and is likely within the gauge measurement uncertainty. This suggests that on average the relation in Eq. (1) with the mean $\mathrm{K}_{\mathrm{a}}$-band coefficients specified above is appropriate, and the MMCR can provide reasonable estimates of snowfall. The spread of radar-based estimates relative to the gauge is, however, significant. The RSD value of $87 \%$ corresponds to an average difference of a little greater than a factor of 2 (i.e., $-50 \%, 100 \%$ ). For some events (e.g., 17 April 1998), the difference is as large as a factor of 3 . These differences suggest a high variability of parameters in the $Z_{e}-S$ relation as a result of significant uncertainties of the snowflake microphysical properties (Matrosov 2007a).

Two examples of the radar-derived liquid equivalent snowfall accumulation time series for representative SHEBA events (26 January and 21 March 1998) are shown in Fig. 5. Unlike the automatic NSA Geonor gauge, which provides accumulations with 0.01 -in. increments, the Nipher gauge at SHEBA was used to provide only one reading daily that could be used to estimate the storm total accumulation. These qualitycontrolled storm total accumulation estimates during SHEBA are, however, expected to be more reliable than automatic readings from the unattended NSA site.

Although snowfall accumulation estimates at the ground from vertically pointing radars are likely to be
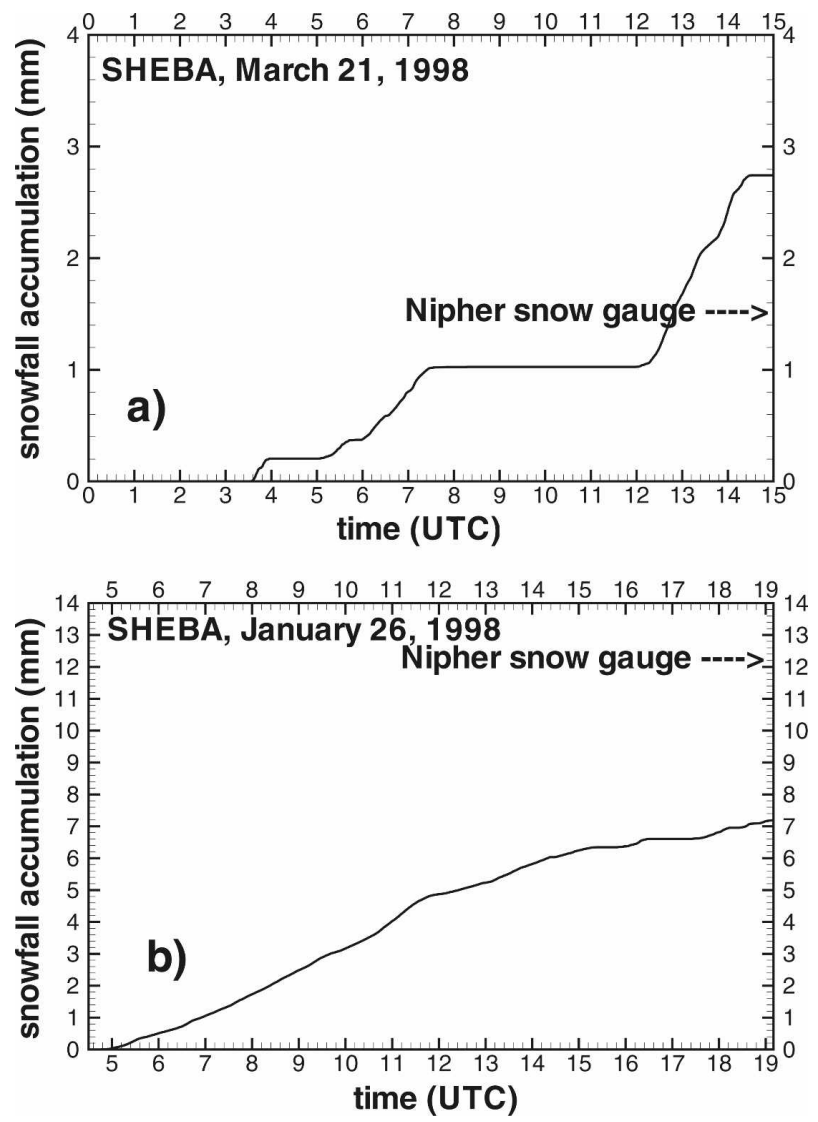

FIG. 5. Time series of snowfall accumulations estimated from MMCR measurements for the SHEBA events observed on (a) 21 Mar and (b) 26 Jan 1998.

inferior to the measurements from quality-controlled snow gauges, radar can provide measurements of instantaneous snowfall rate that are typically not available from standard gauges. In addition, radar provides vertically resolved snowfall information that is potentially useful for a wide range of applications, including precipitation-process and cloud-modeling studies. Particularly important would be measurements of snowfall with spaceborne $\mathrm{K}_{\mathrm{a}}$ band (and $\mathrm{K}_{\mathrm{u}}$ band) radars that are planned for the National Aeronautics and Space Administration (NASA) Global Precipitation Mission (GPM). GPM radars will not be available in the immediate future, but CloudSat already provides satellitebased snowfall observations. Although, because of stronger non-Rayleigh effects, the dynamic range of $\mathrm{W}$-band reflectivities in snow is smaller than that at $\mathrm{K}_{\mathrm{a}}$ band, estimates of snowfall rate can also be made with the CloudSat radar, as illustrated in the next section.

\section{CloudSat estimates of snowfall}

Spaceborne W-band radar measurements provide a unique opportunity to monitor atmospheric hydro- 

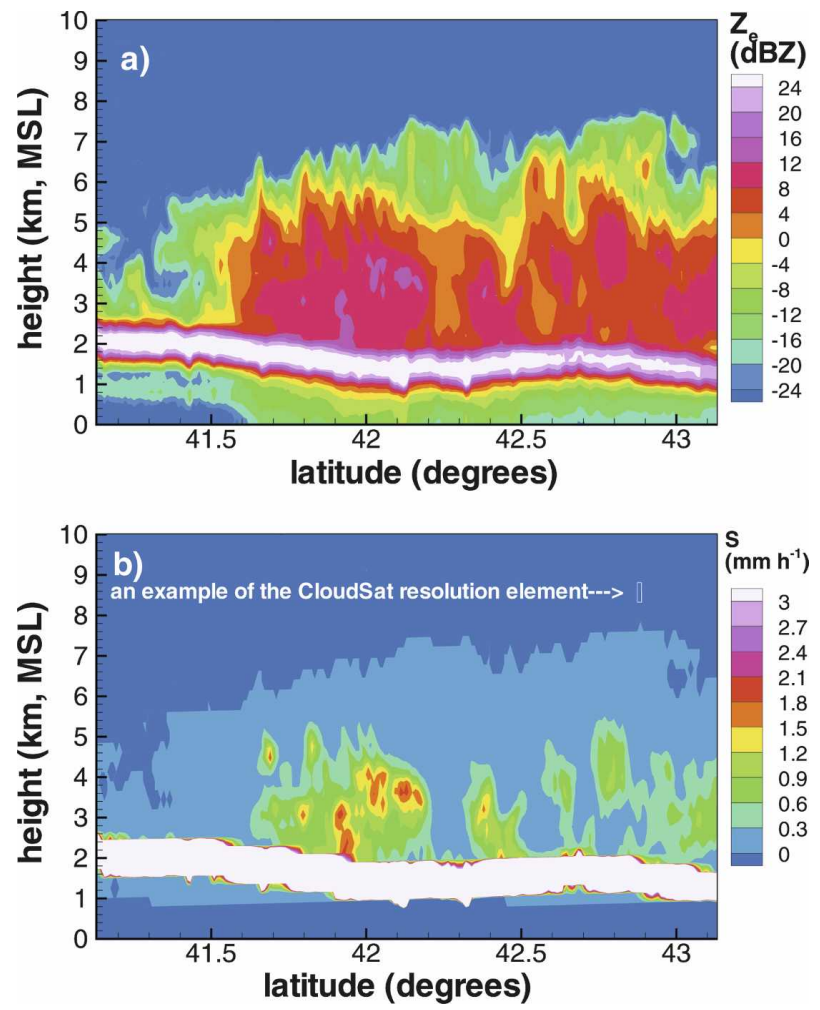

FIG. 6. Cross sections of (a) measured CloudSat reflectivity and (b) estimated snowfall rate for a snowstorm observed in southern Wyoming on 21 Dec 2007.

meteors on a global scale. The $94-\mathrm{GHz}$ frequency is particularly suited for cloud remote sensing, but quantitative precipitation information can also be retrieved from CloudSat measurements. The CloudSat range resolution is about $0.48 \mathrm{~km}$, though measurements are oversampled by a factor of 2 , thus providing one sample every $0.24 \mathrm{~km}$. Unlike in rainfall, attenuation of $\mathrm{W}$ band radar signals in dry snowfall is still relatively small, and therefore $Z_{e}-S$ relations specifically tuned for the $94-\mathrm{GHz}$ frequency can be used for CloudSat snowfall estimates.

Relative to longer-wavelength frequencies, the strong non-Rayleigh scattering at $\mathrm{W}$ band results in a smaller dynamic range of reflectivity changes as snowfall rate varies. Modeling studies (Matrosov 2007a) indicate that at $\mathrm{W}$ band the coefficient $a$ in Eq. (1), depending on the assumptions, could vary in a range between about 7 and 13 , and the exponent $b$ is typically around 0.8 . An average relation [i.e., $Z_{e}\left(\mathrm{~mm}^{6} \mathrm{~m}^{-3}\right)=$ $\left.10 S^{0.8}\left(\mathrm{~mm} \mathrm{~h}^{-1}\right)\right]$ was used here to illustrate snowfall retrievals using CloudSat measurements that are shown below. The CloudSat radar measures reflectivity only, and so a one measurable $\left(Z_{e}\right)$-one retrievable $(S)$ approach appears to be a natural choice.

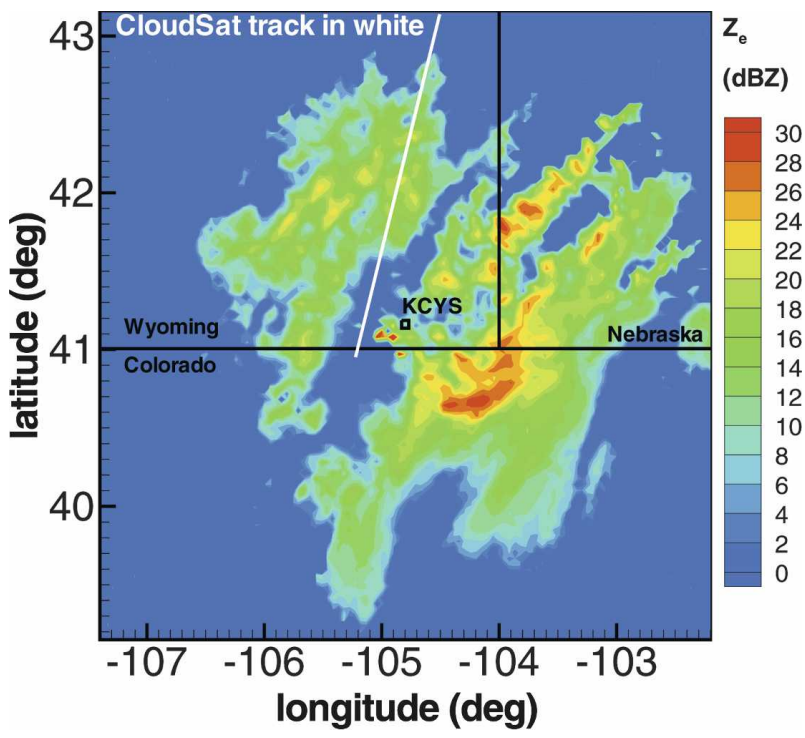

FIG. 7. Radar reflectivity field as measured by the WSR-88D KCYS radar in a heavy snowstorm observed on 21 Dec 2006 in northern Colorado and southern Wyoming.

An example of the CloudSat snowfall measurements is presented in Fig. 6, where a time-height cross section of W-band radar reflectivities (Fig. 6a) and the corresponding estimates of snowfall rate (Fig. 6b) are shown as the satellite crossed over an area of heavy snowfall in northern Colorado and southern Wyoming on 21 December 2006. The layer of increased reflectivity between about 1 and $2 \mathrm{~km}$ above mean sea level (MSL) represents range gates contaminated by ground returns. This event was relatively cold with temperatures in the atmospheric column not exceeding $-6^{\circ} \mathrm{C}$ according to nearby radiosonde sounding. The event was associated with easterly upslope winds and produced one of the largest total snowfall accumulations observed in recent years along the Colorado Front Range and northern plains. The total "solid" snow accumulations at the ground over a period of $24 \mathrm{~h}$ varied from about $40 \mathrm{~cm}$ to more than $1 \mathrm{~m}$, with an average ratio of snow depth to melted water equivalent of about 13:1, which is typical for dry snowfall.

Figure 7 depicts the snowfall echo as measured by the Cheyenne, Wyoming, Weather Surveillance Radar1988 Doppler (WSR-88D), which is a part of the NextGeneration Weather Radar (NEXRAD) network. This NEXRAD radar is located close to the ColoradoWyoming border and has the four-letter site identifier KCYS. The 0914 UTC KCYS azimuthal scan shown in Fig. 7 was performed at $0.5^{\circ}$ radar elevation angle and corresponds to the CloudSat overpass. The CloudSat ground track is also depicted as the solid white line. The satellite was on its descending orbit crossing the Colo- 
rado-Wyoming border just southwest of Cheyenne. KCYS snowfall reflectivities are considerably higher than those from CloudSat because scattering at S-band NEXRAD frequencies $(\lambda \sim 10 \mathrm{~cm})$ is practically within the Rayleigh scattering regime for typical snowflake sizes.

\section{Comparisons of CloudSat and NEXRAD measurements}

For specific radar beam tilts and ranges, Super and Holroyd (1998) developed empirical $Z_{e}-S$ relations for a number of NEXRAD surveillance radars that are located in parts of the United States that often get snowfall during wintertime. In their method development, they used estimates of $S$ that were made in the NEXRAD-covered area by snow boards and/or highquality heated snow gauges located in carefully chosen, wind-protected sites. These estimates were then related to NEXRAD radar measurements of $Z_{e}$ above the gauges. Although the KCYS radar was not included in their study, the Denver, Colorado, NEXRAD (the four-letter site identifier is KFTG) was. Because KFTG radar is located only about $250 \mathrm{~km}$ south from KCYS in a similar environment and both radars are similarly calibrated, the $Z_{e}-S$ relation recommended for KFTG was used here to estimate snowfall rates from KCYS measurements.

The experimental value for the exponent $b$ in Eq. (1) recommended by Super and Holroyd (1998) is 2, which is practically identical to the theoretical findings for S-band frequencies of NEXRAD radars (Matrosov 1992). These authors also suggest that $b$ does not change with the resolution pixel distance from the NEXRAD radar. The coefficient $a$ is generally lower for farther distances than for shorter ranges. For the $0.5^{\circ}$ radar elevation angle, an average value of $a$ in Eq. (1) for KFTG is about 40 at ranges between 60 and 100 $\mathrm{km}$, which are the longest ranges considered by Super and Holroyd (1998) for KFTG. These values of $a$ and $b$ [i.e., $Z_{e}\left(\mathrm{~mm}^{6} \mathrm{~m}^{-3}\right)=40 S^{2}\left(\mathrm{~mm} \mathrm{~h}^{-1}\right)$ ] were used for estimations of snowfall rate from KCYS measurements.

The area of snowfall echo along the CloudSat ground track between latitudes of $41.5^{\circ}$ and $42.5^{\circ}$ (see Fig. 7) is of particular interest for comparisons between spaceborne and NEXRAD ground-based snowfall estimations. The distance between KCYS and the beginning and the end of this area is about 55 and $140 \mathrm{~km}$, respectively. Under normal atmospheric conditions because of refraction and the curvature of the earth, the center of the KCYS beam is located at about $1 \mathrm{~km}$ AGL for the beginning of the comparison area and at about $2 \mathrm{~km}$ for its end. Vertical resolutions of the KCYS beam are around 0.5 and $1 \mathrm{~km}$ at these distances,

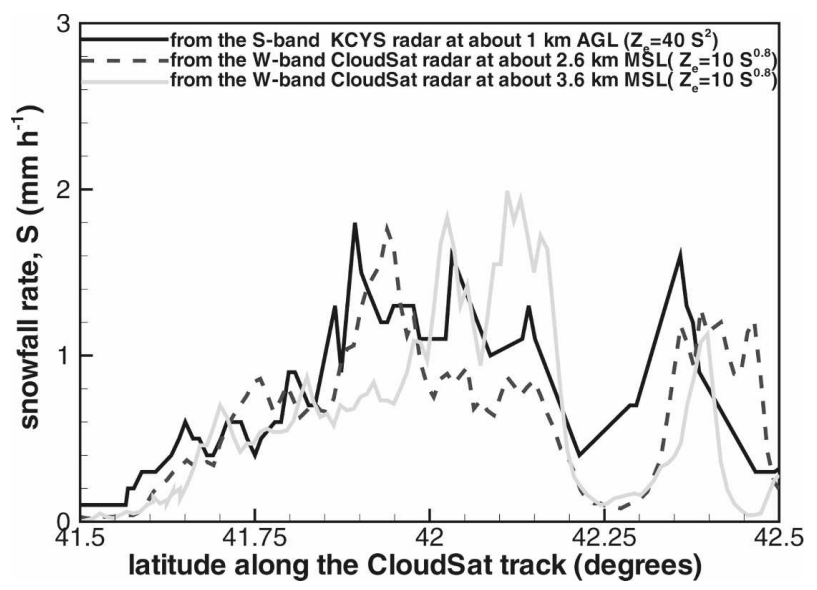

FIG. 8. Comparisons of CloudSat and KCYS WSR-88D estimates of snowfall rate.

respectively. The smaller area of the snowfall echo centered at around $40^{\circ} \mathrm{N}$ and $105.5^{\circ} \mathrm{W}$, which was overpassed by CloudSat, is over the mountainous terrain, and there is a possible partial beam blockage for the ground-based radars.

Figure 8 shows the KCYS estimates of snowfall rate along the CloudSat ground track obtained for the $0.5^{\circ}$ elevation scan presented in Fig. 7. The NEXRAD resolution volumes with ground coordinates that are within $\pm 0.5 \mathrm{~km}$ from the CloudSat ground coordinates were chosen for comparison. Also shown in Fig. 8 are spaceborne snowfall-rate estimates from the CloudSat vertical resolution gates that are the closest to the KCYS resolution volumes, thus providing for the best possible spatial overlapping. Both CloudSat and KCYS snowfall-rate estimates were obtained using their respective $Z_{e}-S$ relations discussed above. In the case of CloudSat, measured radar reflectivities were corrected for gaseous and snowfall attenuations according to Matrosov (2007a).

To provide some information on vertical variability of instantaneous snowfall, CloudSat retrievals are shown for altitudes of 2.6 and $3.6 \mathrm{~km}$ MSL. Estimates at altitudes lower than $2.6 \mathrm{~km}$ MSL might be still contaminated by the ground returns that are seen in Fig. 6 as an elongated area of high reflectivity $(>25 \mathrm{dBZ})$. CloudSat estimates of $S$ at both 2.6 and $3.6 \mathrm{~km}$ MSL are very close except between latitudes $41.9^{\circ}$ and $42.15^{\circ}$ and also after $42.4^{\circ}$. These differences are mainly caused by pockets of higher reflectivity (and, hence, higher estimates of $S$ ), which can be seen in Fig. 6 for latitudes around $42^{\circ}$, and high vertical reflectivity gradients between 3 and $4 \mathrm{~km}$ MSL at around $42.4^{\circ}$. Overall, the instantaneous snowfall parameters exhibit considerably higher vertical variability when compared with the mean profiles as discussed in section 2. Spaceborne 
measurements, however, always provide instantaneous snapshots, and so it is difficult to use them for estimating time-averaged profiles.

It can be seen from Fig. 8 that both CloudSat and KCYS observe similar snowfall patterns. Those patterns include the maximums at latitudes around $41.9^{\circ}-$ $41.95^{\circ}, 42.05^{\circ}, 42.12^{\circ}$, and $42.35^{\circ}$ and a broad minimum at around $42.25^{\circ}$. Overall the CloudSat-KCYS comparison should be considered satisfactory, though at times they differ by as much as a factor of 2 or even greater. Note that CloudSat estimates have significant retrieval errors that are most likely to be at least a factor of 2 that result only from uncertainties in the coefficients of the $Z_{e}-S$ relation (Matrosov 2007a). NEXRAD retrievals of $S$ could have comparable or even higher errors. NEXRAD rainfall retrievals based on $Z_{e}-R$ relations can provide factor-of-2 (or even higher) uncertainties (http://www.nmq.nssl.noaa.gov/). It is also very likely that snowfall estimates from the NEXRAD $Z_{e}-S$ relations (Super and Holroyd 1998) have higher uncertainties than these rainfall retrievals because of a higher variability in snowflake microphysical properties relative to those of raindrops.

Given relatively high retrieval uncertainties for both spaceborne and ground-based radar estimates of snowfall rate, the comparison given above cannot be regarded as a strict validation effort, but it is useful as a consistency check. Note also that ground-based radars such as NEXRAD radars provide one of only few options for quantitative comparisons for precipitation retrievals using CloudSat measurements. Precipitation gauges typically provide accumulation amounts and cannot be effectively used for comparisons of instantaneous precipitation rates from CloudSat retrievals.

\section{Summary and conclusions}

This study illustrates the utility of $\mathrm{K}_{\mathrm{a}^{-}}(\lambda \sim 8.6 \mathrm{~mm})$ and $\mathrm{W}$-band $(\lambda \sim 3.2 \mathrm{~mm})$ millimeter-wavelength vertically or nadir-pointing radars to provide quantitative information on snowfall. Such radars have been primarily designed and used for nonprecipitating cloud research, but their measurements can also be used for precipitation retrievals that include snowfall. A number of vertically pointing $\mathrm{K}_{\mathrm{a}}$-band radars are deployed as part of cloud-observing-instrument suites in locations that regularly receive solid precipitation. Adding a snowfall retrieval capability for such radars will enhance their remote sensing performance and provide a more complete characterization of the vertical atmospheric column, which is one of the most important objectives of the ARM Program. Airborne and, especially, spaceborne $\mathrm{W}$-band radars can provide global information on snowfall that is not yet available from other means.

Relations between radar reflectivity $Z_{e}$ and liquid equivalent dry snowfall rate $S$, which had been specifically developed for $\mathrm{K}_{\mathrm{a}}$ and $\mathrm{W}$ bands (Matrosov 2007a), were applied to measurements from the vertically pointing $\mathrm{K}_{\mathrm{a}}$-band radars operated in the Arctic and to the measurements of the spaceborne $\mathrm{W}$-band radar (CloudSat). The snowfall estimates obtained with millimeter-wavelength radars were then compared with available ground-based measurements from qualitycontrolled snow gauges (for the $\mathrm{K}_{\mathrm{a}}$-band MMCR radar) and with remote measurements from the standard weather surveillance radars that are routinely used for precipitation observations (for the W-band CloudSat radar).

Statistical comparisons of MMCR retrievals of dry snowfall accumulations using the mean $\mathrm{K}_{\mathrm{a}}$-band relation $\left(Z_{e}=56 S^{1.2}\right)$ with gauge data provided the mean bias of radar-derived estimates of only $23 \%$ and the relative standard deviation of $87 \%$. Such an RSD value is consistent with the variability of the $Z_{e}-S$ relation from uncertainties in the model assumptions and reflects a possible error of radar-derived snowfall parameters. Unlike any other instruments typically deployed at cloud observatories, MMCR profiling radars provide unique vertically resolved information on snowfall that can be used for better understanding precipitationformation processes and elements of the water cycle.

Despite strong non-Rayleigh scattering at $\mathrm{W}$ band and hence a reduced dynamic range of reflectivity variability, the CloudSat radar nadir-pointing measurements can be used to estimate dry snowfall rate with a $Z_{e}-S$ relation that is specifically tailored for the 94$\mathrm{GHz}$ frequency. For a case study of heavy snowfall in northern Colorado-southern Wyoming, results obtained with a model relation $\left(Z_{e}=10 S^{0.8}\right)$ were found to be generally within a factor of 2 with ground-based estimates available from the KCYS weather surveillance radar. This radar is a part of the NEXRAD network specifically designed for observation and measurement of precipitation and severe weather. Whereas CloudSat-NEXRAD estimates of $S$ sometimes differ by a factor of 2 or even greater, the discrepancy between these estimates of instantaneous snowfall rates was typically within the uncertainties of both retrievals. Although it is not a strict validation of CloudSat retrievals, this comparison provides evidence of the mutual consistency of spaceborne cloud and ground-based precipitation radar measurements of snowfall and suggests that CloudSat can provide unique information on global snowfall. Unlike for ground-based vertically pointing cloud radars, collocated standard snow gauge 
measurements that estimate accumulations cannot be used for direct quantitative validating purposes for CloudSat because of the instantaneous nature of spaceborne measurements and long revisit times.

Overall, this study indicates that the use of cloud millimeter-wavelength radars operating at $\mathrm{K}_{\mathrm{a}}$ and $\mathrm{W}$ bands can be extended to snowfall studies. The $Z_{e}-S$ relations tuned to these wavelengths present a viable option to estimate liquid equivalent snowfall rate when attenuation effects are relatively small. Cloud radarbased snowfall retrievals were found to be consistent with estimates from more established methods (snow gauges and precipitation radars). Because this is an initial attempt to assess snowfall retrievals from millimeter-wavelength radars quantitatively and the considered dataset is relatively small, more intercomparison studies and retrieval results are needed in the future to understand better the quantitative uncertainties of cloud radar-based snowfall retrievals.

Acknowledgments. This research was supported by Grant DE-FG02-05ER63954 of the Office of Science (Biological and Environmental Research) of the U.S. Department of Energy and by the NASA Project NNX07AQ82G.

\section{REFERENCES}

Bringi, V. N., and V. Chandrasekar, 2001: Polarimetric Doppler Weather Radar. Cambridge University Press, 636 pp.

Goodison, B. E., and D. Yang, 1996: In situ measurement of solid precipitation in high latitudes. Proc. Workshop on the ACSYS Solid Precipitation Climatology Project, WCRP-93, WMO/TD-739, Reston, VA, WMO, 3-17.

Kollias, P., B. A. Albrecht, E. E. Clothiaux, M. A. Miller, K. L. Johnson, and K. P. Moran, 2005: The Atmospheric Radiation Measurement Program cloud profiling radars: An evaluation of signal processing and sampling strategies. J. Atmos. Oceanic Technol., 22, 930-948.
Mace, G. G., A. J. Heymsfield, and M. Poellot, 2002: On retrieving the microphysical properties of cirrus clouds using moments of millimeter wavelength Doppler spectrum. J. Geophys. Res., 107, 4815, doi:10.1029/2001JD001308.

Matrosov, S. Y., 1992: Radar reflectivity in snowfall. IEEE Trans. Geosci. Remote Sens., 30, 454-461.

- 2005: Attenuation-based estimates of rainfall rates aloft with vertically pointing $\mathrm{K}_{\mathrm{a}}$-band radars. J. Atmos. Oceanic Technol., 22, 43-54.

_ 2007a: Modeling backscatter properties of snowfall at millimeter wavelengths. J. Atmos. Sci., 64, 1727-1736.

_ 2007b: Potential for attenuation-based estimations of rainfall rate from CloudSat. Geophys. Res. Lett., 34, L05817, doi:10.1029/2006GL029161.

— A. V. Korolev, and A. J. Heymsfield, 2002: Profiling cloud mass and particle characteristic size from Doppler radar measurements. J. Atmos. Oceanic Technol., 19, 1003-1018.

— , P. T. May, and M. D. Shupe, 2006: Rainfall profiling using Atmospheric Radiation Measurement Program vertically pointing 8-mm wavelength radars. J. Atmos. Oceanic Technol., 23, 1478-1491.

Mitchell, D. L., 1988: Evolution of snow-size spectra in cyclonic storms. Part I: Snow growth by vapor deposition and aggregation. J. Atmos. Sci., 45, 3431-3451.

— , and A. J. Heymsfield, 2005: Refinements in the treatment of ice particle terminal velocities, highlighting aggregates. J. Atmos. Sci., 62, 1637-1644.

Mosimann, L., 1995: An improved method for determining the degree of snow crystal riming by vertical Doppler radar. Atmos. Res., 37, 305-323.

Shupe, M. D., S. Y. Matrosov, and T. Uttal, 2006: Arctic mixedphase cloud properties derived from surface-based sensors at SHEBA. J. Atmos. Sci., 63, 697-711.

Stephens, G. L., and Coauthors, 2002: The CloudSat mission and the A-train: A new dimension of space-based observations of clouds and precipitation. Bull. Amer. Meteor. Soc., 83, 17711790 .

Super, A. B., and E. W. Holroyd, 1998: Snow accumulation algorithm for the WSR-88D radar: Final report. U.S. Department of the Interior, Bureau of Reclamation, R-98-5, 75 pp.

Uttal, T., and Coauthors, 2002: Surface Heat Budget of the Arctic Ocean. Bull. Amer. Meteor. Soc., 83, 255-275. 